\title{
Propostas para Aumento do Desempenho da Área de Compras em Empresa Varejista
}

\author{
Rosangela Vilela dos Santos ${ }^{1}$, Luiz Alberto Nascimento Campos Filho ${ }^{2}$ \\ ${ }^{1}$ CasaShow - Gerente de Compras - Rod.Pres. Dutra, 4.674 - 25.569-900 - São João de \\ Meriti-RJ, Brasil, rosangelav@casashow.com.br \\ ${ }^{2}$ Faculdades Ibmec Rio - Professor Adjunto - Av. Pres. Wilson, 118 - Sala 1113 - \\ 22.030-020 - Rio de Janeiro - RJ, Brasil, camposfo@gmail.com
}

\section{Resumo}

O varejo de material de construção no Brasil passou por várias transformações com a chegada de novos concorrentes, a partir do final da década de 90. A competitividade do setor passou a depender da gestão eficiente de suas operações e principalmente, da área de Compras. A presente pesquisa teve como principal objetivo a elaboração de propostas para que poderão aumentar o desempenho da área de compras. Foi realizado um estudo de caso em empresa varejista líder na venda material de construção no Rio de Janeiro. $\mathrm{O}$ diagnóstico mostrou que a área de compras da empresa analisada ainda exerce um papel operacional, apresentando a necessidade de mudanças neste departamento.

Palavras-chave: compras, Cadeias de suprimento, varejo, material de construção.

\begin{abstract}
The arrival of new competitors in the construction materials market caused many changes since the end of 90 decade. The competitiveness of this sector started to depend on the efficiency of their operations and mainly of the purchasing department. The main goal of this research was the development of proposals that could increase the purchasing department performance. It was performed a case study in construction material company, leader in sales in Rio de Janeiro. The diagnosis showed that the analyzed purchasing department is still operational. There is a need of change in this department.

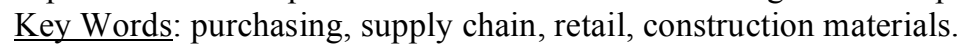

\section{Introdução}

A chegada de novos concorrentes (Leroy Merlin e C\&C) no segmento de material de construção promoveu várias transformações, nos estados do Rio de Janeiro e São Paulo, a partir do final da década de 90. A competitividade aumentou, as margens de lucro decresceram e as empresas que já atuavam no mercado perderam poder de barganha junto aos fornecedores.

Neste cenário, a manutenção da competitividade destas empresas passou a depender da gestão eficiente de suas operações e, principalmente, da área de Compras.

Responsáveis por adquirir produtos que correspondem a mais de $70 \%$ do faturamento da empresa, as áreas de compras das lojas de materiais de construção terão como principais missões: reduzir custos e fornecer vantagens competitivas que garantam a sobrevivência da organização [12].

Porém, esta missão não é fácil. Marcadas por um grande número de atividades rotineiras, pouca relação com a estratégia da empresa e dispondo de relacionamentos adversários com os fornecedores, as áreas de compras do varejo de material de construção ainda exercem um papel meramente operacional.

Dentro deste contexto, foi realizado um estudo de caso em uma empresa varejista de material de construção, de origem familiar, nacional, líder do seu segmento no Rio de Janeiro. A presente pesquisa teve como principal objetivo elaborar propostas que poderão aumentar o desempenho da área de compras. Para a realização deste objetivo, foi necessário: (1) identificar as principais mudanças ocorridas na área de compras da referida empresa, após a entrada da concorrência, em relação aos quatro tópicos estratégicos: planejamento de 
compras, estrutura organizacional, relacionamento com fornecedores e sistemas de informação e (2) diagnosticar o estágio atual de evolução da área de compras.

A presente pesquisa é uma contribuição para a prática e constituirá um estudo qualitativo com caráter exploratório. Trata-se de um estudo de caso único com a utilização de questionários e entrevistas com profissionais envolvidos com a função compras.

$\mathrm{O}$ artigo está organizado em seis seções. Sendo a primeira e a última, introdução e considerações finais com sugestões para futuros trabalho. Após esta introdução, a opção metodológica e suas limitações são apresentadas. A seção três versa sobre a revisão da bibliografia em Compras e Tópicos Estratégicos. Em seguida, sendo apresentado a seção do estudo de caso e as propostas para aumento do desempenho da área de compras.

\section{Metodologia}

A metodologia escolhida para a presente pesquisa foi o Estudo de Caso. O método do estudo de caso surge como método potencial da pesquisa quando se deseja investigar um fenômeno contemporâneo dentro do seu contexto de vida real, dado que as fronteiras entre o fenômeno e o contexto não são claramente visíveis [15].

O estudo de caso permite o aprofundamento da análise do assunto, possui foco na compreensão dos fatos e não na sua mensuração [7]. O foco deste estudonão será quantificar as práticas que permitem a evolução da área de compras e sim, compreender quais práticas podem contribuir para o aumento do desempenho da área de compras.

$\mathrm{O}$ estudo de caso foi apoiado por uma pesquisa bibliográfica, que identificou na literatura, os conceitos e princípios do modelo teórico, que auxiliaram na elaboração do plano geral de pesquisa.

Viéses também podem ser inseridos em outros procedimentos metodológicos e que os estudos de casos são generalizáveis a proposições teóricas, e não à populações e universos [15].

A primeira etapa da pesquisa compreendeu a fase de definição e planejamento. Nesta etapa, foi realizada uma revisão da bibliografia sobre Compras e selecionado o estudo de caso que seria objeto do presente estudo.

A empresa escolhida foi uma empresa varejista de material de construção, de estrutura familiar, nacional e líder no seu segmento no Rio de Janeiro. A seleção desta empresa deveu-se a dois fatores: (1) apesar da entrada da concorrência, esta empresa ainda mantém a liderança dentro de seu segmento [3], (2) a principal autora do trabalho exerce o cargo de Gerente de Compras na empresa analisada, o que permitiu um maior aprofundamento do tema em estudo.

A segunda etapa do trabalho foi a fase de preparação, coleta e análise. Esta etapa consistiu na seleção das fontes de evidências, na elaboração do roteiro de entrevistas e na análise do relatório do Estudo de caso.

As fontes de evidências selecionadas para a análise do caso proposto, foram:

$\checkmark$ Documentação - Exemplos: artigos em jornais, revistas, estudos feitos por consultorias na empresa analisada.

$\checkmark \quad$ Registros em arquivos - Exemplos: tabelas de orçamentos da empresa.

$\checkmark \quad$ Entrevistas - Foram feitas três entrevistas com os executivos da empresa analisada (Presidente, Diretor Geral e Comprador da categoria tintas). As entrevistas foram feitas pessoalmente e cada entrevista teve a duração aproximada de 40 minutos. Abaixo, a tabela 1, mostra os perfis dos entrevistados.

\begin{tabular}{|l|l|l|}
\hline Cargos & Tempo na empresa & \multicolumn{1}{c|}{ Formação Acadêmica } \\
\hline Presidente & Desde a sla fundação & $1^{0}$ graul \\
\hline Diretor Geral & 4 anos & Superior complett Administração, MBA marketing \\
\hline Comprador da categoria tintas & 10 anos & Superior completo Administração \\
\hline
\end{tabular}

Tabela 1. Perfil dos entrevistados

$\mathrm{Na}$ condução das entrevistas, foram aplicados dois roteiros. O roteiro 1 foi utilizado nas entrevistas com o Diretor e o comprador da categoria. Neste roteiro foram abordadas questões específicas ao departamento de compras e aos quatro tópicos estratégicos (planejamento de compras, relacionamento com fornecedores, estrutura organizacional e sistemas de informação). A elaboração deste roteiro teve como base os seguintes documentos:

- Pesquisa que a CAPS (Center Advanced for Purchasing Studies) empreendeu para diagnosticar as melhores práticas em compras [4].

- Dissertação de Ana Flavia Chaves apresentada à USP para obtenção do título de mestrado, com o título: Estudo das variáveis utilizadas na decisão de compras no comércio varejista de alimentos de autoserviço [2].

- Tese de José Carlos Lima em 2004 apresentada à USP para a obtenção do título de doutor, com o título: Um estudo sobre a reconfiguração da função compras em empresas do setor automotivo [7].

$\mathrm{O}$ roteiro 2 foi utilizado na entrevista com o Presidente da empresa. Neste roteiro foram abordadas questões à respeito da origem da empresa, mudanças organizacionais realizadas após a entrada da concorrência, gestão de compras e planos da empresa para os próximos 5 anos.

A análise do relatório do Estudo de caso foi realizada comparando a prática empresarial e o que vem sendo preconizado na teoria sobre compras e tópicos estratégicos.

A parte final da pesquisa foi a elaboração do diagnóstico e das propostas para o aumento do desempenho da área de compras da empresa analisada.

Limitações teórica e metodológica

A pesquisa possui limitação teórica e metodológica. No que se refere à limitação teórica, o presente trabalho não estuda todas as variáveis 
propostas pelo CAPS, para entendimento das melhores práticas em compras.

The Center for Advanced Studies in Purchasing (CAPS) afirma que:

"o entendimento do cenário atual e das mudanças que aconteceram em relação aos tópicos de planejamento de compras, relacionamento com fornecedores, sistemas de informação, meio ambiente, terceirização, estrutura organizacional e compras globais ajudam o entendimento das melhores práticas em Compras [4]."

$\mathrm{Na}$ presente pesquisas, quatro fatores foram abordados. São eles: planejamento de compras, relacionamento com fornecedores, estrutura organizacional e sistemas de informação. A escolha destes quatro tópicos deveu-se ao fato de que os assuntos de terceirização, compras globais e meio ambiente estão mais relacionados às empresas industriais, na opinião dos autores do trabalho.

No que se refere às limitações metodológicas, a restrição é em relação ao estudo de caso único. Porém, o estudo de caso único mostrou-se adequado por dois motivos: (1) o objetivo era capturar as circunstâncias e condições de uma situação lugarcomum ou do dia a dia, ou seja, o funcionamento de uma área de compras de empresa de varejo considerada típica em seu segmento, (2) os pesquisadores tiveram a oportunidade de observar e analisar o problema, através da observação participante.

\section{Revisão da Literatura}

Nesta seção, são descritos os trabalhos e opiniões de autores em torno do tema central da pesquisa, bem como as análises críticas do autor do trabalho. Primeiramente, foi abordado o tema Compras. A segunda parte da revisão bibliográfica abordou os quatro tópicos estratégicos em Compras (planejamento de compras, relacionamento com fornecedores, estrutura organizacional e sistemas de informação) e os modelos de evolução da área de compras.

\subsection{Compras}

A atividade de compras consiste em obter do exterior da empresa os materiais, produtos e os serviços necessários a seu funcionamento, nas quantidades e prazos estabelecidos, respeitando os níveis de qualidade predefinidos e, ao menor preço que seja possível no mercado [2]. O termo Compras refere-se ao gerenciamento das atividades diárias do fluxo de materiais [8]. A atividade de compras é o processo pelo qual as empresas definem os itens a serem comprados, identificam e comparam os fornecedores disponíveis, negociam com as fontes de suprimentos, firmam contratos, elaboram ordens de compras e finalmente, recebem e pagam os bens e serviços adquiridos [1].

O papel de Compras modificou-se muito. Até a década de 70, as áreas de compras estavam restritas a um papel operacional dentro das organizações. A função básica de compras era: comprar materiais e serviços externos para atender as necessidades dos usuários.

Até a década de 70, este sistema gerou eficiência. Porém, com o passar do tempo e o aumento do volume de transações, o departamento de compras limitou-se a processar pedidos de compras. Grande número de fornecedores, alto número de atividades que não agregavam valor e processos altamente padronizados originaram um grande número de atividades burocráticas, que impediram a existência de um pensamento estratégico sobre o negócio da empresa [12].

A partir da década de 80 , sob a influência da filosofia japonesa Just in time, muitas empresas norteamericanas e brasileiras, começaram a adotar a compra em pequenos lotes.

A partir da década de 90, a globalização, a reengenharia de atividades, o aumento da competição e a pressão para redução de custos, fizeram com que a atenção das empresas fosse desviada para a área de Compras. "A partir de agora, irá existir um grande beneficio das relações entre as empresas e seus fornecedores. Esta oportunidade será fonte de vantagem competitiva e não pode mais ser negligenciada” [1].

Dentre os fatores que contribuíram para o aumento da importância da área de Compras a partir da década de 90, pode-se citar: [1], [7], [8], [6].

a) A reengenharia de processos - A reengenharia de processos fez com que as abordagens interfuncionais superassem as antigas visões funcionais dentro da organização. Esta abordagem fez com que a área de Compras tivesse foco no processo interfuncional e não apenas na função isolada de compras.

b) $\mathbf{O}$ fracasso das técnicas tradicionais de reduções de custos - As empresas mediante a competição global buscaram meios de reduzir custos de mão de obra, processos e materiais. A área de compras tentou reduzir custos através de árduas negociações com fornecedores e da adoção de práticas de terceirização. O fracasso das práticas mais usadas de redução de custos gerou a necessidade de obtenção de outras formas de extração de valor da área de compras [8].

c) $O$ fracasso das relações adversárias com fornecedores - $\mathrm{O}$ exemplo da relação de colaboração com fornecedores das indústrias japonesas mostrou-se mais adequado para o contexto atual, do que a tradicional abordagem de adversários. As áreas de compras começaram a preocupar-se a entregar maior valor para o cliente final [6].

$\mathrm{O}$ grande avanço da tecnologia fez com que o conceito de compras fosse visto como um processo contínuo que visava integrar os fornecedores aos processos da organização. Deste modo, seria possível, adquirir vantagens competitivas oriundas de reduções de custos, desenvolvimento tecnológico, melhoria da qualidade e redução do tempo do ciclo de desenvolvimento dos produtos [1].

Apesar da constatação da necessidade de transformação, as mudanças ainda são lentas e o foco 
da área de compras ainda reside em processos funcionais [6].

A visão de compras está mudando, de uma função que executava apenas atividades operacionais para uma função mais estratégica que contribui efetivamente para o sucesso da organização [8].

A percepção de que a função compras não é mais uma atividade rotineira de administração de "pedidos", está mais reconhecida. Neste novo cenário, a área de Compras passa a ter um papel pró-ativo em contraste com o antigo papel reativo que desempenhava [1]. Conforme Riggs \& Robbins [12], "É preciso repensar o processo de compras, substituindo o sistema moroso e antiquado por um processo gerencial simples que crie valor em cada compra".

\subsection{Compras no Varejo}

Os objetivos da atividade compras são amplos e atendem a todos os tipos de empresas, industriais e varejistas. Porém, no varejo, além das atividades tradicionais, a área de compras deve conhecer as necessidades dos consumidores locais e definir o mix de produtos adequado a cada região.

A fim de ilustrar um erro de mix que é clássico no varejo, pode-se citar o caso da empresa Wal Mart. Ao se instalar no Brasil, a empresa não teve sucesso. Como motivo principal pode-se citar a oferta de produtos que não condiziam com os gostos $\mathrm{e}$ preferências dos consumidores brasileiros, como por exemplo: sacolas para sacos de golfes, colete salvavida, ou seja, produtos que não faziam parte dos hábitos de consumo brasileiros [9].

Além de se preocupar com a definição do mix correto à cada loja, a elevada competição no comércio varejista faz com que as lojas precisem ter uma área de compras eficiente, uma vez que os gastos com aquisição de mercadorias representam mais de $70 \%$ do faturamento da empresa [12].

Desta maneira, a atividade de compras passa a ser fundamental para a manutenção da competitividade da organização [2].

A área de compras deve ser responsável por [10], [2]:

a) Dirimir a dicotomia existente entre a redução máxima do volume estocado e a falta de produtos - $\mathrm{O}$ conhecimento da rotatividade dos produtos auxiliará a efetuar as compras no volume adequado de sua demanda, considerando uma quantidade de segurança que evite a falta de produtos.

b) Conduzir negociações com fornecedores que assegurem a disponibilidade dos produtos no tempo, quantidade, qualidade e custo adequados - Os interesses conflitantes da negociação têm que ser bem administrados para que tanto o comprador e o fornecedor fiquem satisfeitos. De um lado, o comprador quer obter as melhores condições de fornecimento. De outro lado, o fabricante quer preservar sua lucratividade.

\subsection{Tópicos Estratégicos em Compras}

Conforme já visto, desde a década de 90, as organizações tornaram-se mais conscientes do papel estratégico que a área de compras pode desempenhar em uma organização.

Possuir uma área de compras com foco estratégico pode ser uma fonte de vantagem competitiva para a organização, ao reduzir o desperdício da cadeia de valor. Porém, a maioria das empresas ainda tem dúvidas de como fazer esta evolução.

The Center for Advanced Studies in Purchasing (CAPS) assegura que "o entendimento do cenário atual e das mudanças que ocorreram em relação aos tópicos de (1) planejamento de compras, (2) relacionamento com fornecedores, (3) sistemas de informação, (4) meio ambiente, (5) terceirização e (6) estrutura organizacional e (7) global sourcing, ajudam o entendimento das melhores práticas em Compras" [4].

Para o presente estudo, foram selecionados quatro tópicos, que na avaliação do autor do trabalho são os mais apropriados para diagnosticar a evolução da área de compras dentro das empresas varejistas brasileiras. Os tópicos selecionados foram: (1) planejamento de compras, (2) relacionamento com fornecedores, (3) estrutura organizacional e (4) sistemas de informação. Os tópicos restantes: meio ambiente, terceirização e global sourcing estão mais relacionados com empresas industriais, na opinião do autor do trabalho.

\subsubsection{Planejamento de Compras}

A área de Compras deve possuir um planejamento de compras que garanta a otimização de resultados e a conquista de vantagens competitivas para a organização [5].

Dentro de uma empresa varejista, dois tópicos serão fundamentais para a elaboração de um bom planejamento de compras: o orçamento de compras e a gestão de estoques [10].

\section{a) Orçamento de Compras}

O orçamento de compras de uma empresa varejista define o valor a ser comprado mensalmente pela empresa em função do volume de vendas previsto e estabelece os objetivos de venda, margem e níveis de estoque desejados pela empresa.

Elaborar um bom orçamento de compras ainda é uma tarefa difícil para a maioria das empresas varejistas, uma vez que as mudanças no cenário econômico, nos gostos dos consumidores e na alteração do padrão de compra, podem afetar o volume de vendas e conseqüentemente, exigir mudanças nas quantidades a serem compradas. No caso do segmento de material de construção, esta previsão é ainda mais difícil, pois se o consumidor estiver com a sua renda comprometida com alimentação, educação e moradia, os gastos com a reforma da casa, podem ser adiados. Após definição do orçamento anual da área de compras, as empresas varejistas definirão as metas de compras para o período.

\section{b) Gestão de estoques}


Além da elaboração do orçamento de compras, a gestão de estoques é outro importante elemento no planejamento de compras.

Em função do elevado custo de oportunidade de capital que os estoques representam, o varejo precisa reduzir estoques [13].

$\mathrm{Na}$ gestão de estoque, existem três variáveis que são importantes para o controle gerencial. São elas: giro de estoque, curva $\mathrm{ABC}$ e freqüência de compras.

Outra questão importante para Compras e para a gestão eficiente de estoques é a quantidade e a periodicidade das compras, ou seja, quanto deve ser comprado e com que freqüência.

Conforme Wanke [14], alguns autores argumentam que o lote econômico de compra é uma abordagem que foi ultrapassada pela filosofia Just in Time. A principal diferença entre as duas abordagens é que o lote econômico assume que os custos de processamento do pedido são dados do sistema. Por outro lado, a filosofia Just in Time faz o caminho inverso: dado que o tamanho ideal do lote é o unitário, ela estuda como reduzir o custo de processamento do pedido.

\subsubsection{Relacionamento com Fornecedores}

A fim de criar uma tipologia de relacionamentos com os fornecedores, a empresa de consultoria Booz - Allen \& Hamilton identificou quatro tipos de relações [6]:

$\mathrm{O}$ primeiro tipo seria a abordagem Darwiniana. Neste tipo de abordagem, clientes e fornecedores são vistos como adversários. Este tipo de relacionamento é utilizado por profissionais de compras que acreditam que a realização de negociações beligerantes ainda é a ferramenta mais adequada para conseguir extrair benefícios dos fornecedores. $\mathrm{O}$ ponto negativo desta abordagem é a geração de instabilidade nos fornecedores, que não são estimulados a cooperar.

A segunda abordagem é o relacionamento de confiança com os fornecedores. As empresas acreditam que através deste tipo de relacionamento, os fornecedores podem conceder maior valor aos clientes. Porém, argumenta-se que esta abordagem também tenha pontos negativos, uma vez que ela assume que o fornecedor já atingiu os objetivos esperados, não estimula melhorias e gera um tipo de "confiança cega".

O terceiro tipo de relacionamento é pouco usado pelas empresas, atualmente. A abordagem chamada de não alavancagem dos fornecedores é um tipo de relacionamento que pressupõe a inexistência de negociações com fornecedores e reflete o antigo papel do comprador, de "tirador de pedidos" [6].

Finalmente, o quarto modelo é chamado de Balanced Sourcing. Este tipo de relacionamento pressupõe a existência balanceada de relação de confiança e preços competitivos. A otimização da base de fornecedores, a criação de um sistema de medição de desempenho de fornecedores e a criação de relacionamentos de longo prazo são alguns dos instrumentos utilizados neste tipo de relacionamento [8].

A evolução de uma relação darwiniana para uma relação de Balanced Sourcing será um instrumento relevante para a obtenção de resultados, à medida que os fornecedores "parceiros" sentem-se estimulados a apresentar propostas de melhorias, contribuindo para o bom desempenho da empresa.

\subsubsection{Estrutura organizacional}

Além de estar integrada aos objetivos estratégicos da empresa, ter um bom relacionamento com fornecedores, a estrutura organizacional de compras é um forte impulsionador para a evolução da área de Compras.

A estrutura organizacional de compras engloba dois fatores: os recursos humanos que são empregados na empresa e o grau de centralização das compras.

A definição da estrutura organizacional de compras de uma empresa será fundamental para o desempenho da organização. Uma estrutura organizacional deficiente fará com que o bom desempenho de uma organização seja uma tarefa difícil [1]. Acrescentam que não existe uma estrutura organizacional de aplicação geral. Portanto, torna-se necessário a análise de vários aspectos: tamanho da organização, tipo de mercado a que ela se destina, tecnologia, processos envolvidos, tipo de pessoas empregadas e a volatilidade dos mercados para definir a estrutura de compras adequada.

A estrutura organizacional de uma empresa que possui seis grupos de produtos diferentes, vendidos em mercados diferentes, precisará ser diferente da empresa que possui produto único, por exemplo.

Quanto ao grau de centralização das compras, Baily [1]propõe que a maioria das empresas pode ser classificada, conforme abaixo:

$\checkmark \quad$ Descentralização total, com autonomia plena em cada uma das unidades. É vantajosa quando as lojas estão longe da central de compras. As principais vantagens são: maior conhecimento do mercado local e maior agilidade. A principal desvantagem é a perda do poder de barganha junto aos fornecedores, em virtude dos menores valores negociados.

$\checkmark \quad$ Centralização total, com todas as compras sendo feitas a partir de um escritório central. As principais vantagens são: o maior volume de compras gera poder de barganha junto aos fornecedores e facilita a concessão de descontos, durante a negociação. Existe também um controle mais efetivo em relação ao gerenciamento dos produtos, como acompanhamento do giro e análise de estoque.

\section{$\checkmark$ Combinação de descentralização /} centralização, com algumas compras sendo feitas pelo escritório central e outras de forma descentralizada. $\mathrm{O}$ sistema combina a vantagem da centralização para negociação de grandes volumes com a agilidade da descentralização para atender eficazmente às necessidades e peculiaridades do mercado local de cada loja. 
Conforme Chaves [2], a maioria dos pequenos varejistas adota a modalidade de centralização em virtude dos benefícios da negociação de volumes maiores, dispor de pessoal especializado, garantir a homogeneidade na qualidade de materiais adquiridos e conseguir maior controle de estoque.

No tocante aos recursos humanos empregados na gestão de Compras, Chaves [2] assegura que o perfil do comprador do varejo está mudando. Além de ser o responsável pelo abastecimento das lojas, o comprador deve ajudar a vender os produtos e orientar sobre a melhor exposição no ponto de venda.

Algumas empresas varejistas de maior porte possuem além dos compradores, os gerentes de produtos ou chefes de setor. Estes funcionários estão diariamente nas lojas e são responsáveis [10] por:

$\checkmark$ Informar ao comprador aspectos mercadológicos e financeiros dos produtos.

$\checkmark \quad$ Fornecer informações dos produtos e das características do mercado consumidor.

$\checkmark \quad$ Melhorar a forma de exposição dos produtos.

$\checkmark \quad$ Fazer campanhas promocionais junto aos fornecedores.

\subsubsection{Sistema de informação}

Na gestão de compras, a utilização de sistemas de software integrados (ERP - Enterprise Resource Planning) e dos programas de resposta rápida têm promovido grandes mudanças.

$O$ uso da tecnologia ERP, ao permitir a adoção do conceito de base de dados única, auxilia o gerenciamento dos negócios empresariais e diminui a necessidade de retrabalho para a integração das informações das diferentes áreas.

Os programas de resposta rápida são iniciativas que começaram a ser desenvolvidas por clientes e fornecedores com o objetivo de redesenhar o fluxo de produtos e, por conseqüência, as operações de produção e distribuição através de um maior compartilhamento de informações [13].

A adoção destes programas permite 0 reabastecimento do estoque do varejista em um curto espaço de tempo. Diferente dos sistemas de reposição tradicionais, que levavam semanas para efetuar o ciclo de reposição do pedido (período entre a data do pedido e a chegada do material na loja), os sistemas de reposição automática agilizam o processo e diminui a quantidade de produtos em falta no ponto de venda.

A flexibilidade dos programas de resposta rápida permitem aos varejistas prever hoje o que venderão amanhã e ter as mercadorias nas lojas, na hora, nas quantidades, cores, tamanhos e estilos corretos [10].

Parente [10] complementa que os objetivos dos programas de resposta rápida são:

$\checkmark \quad$ Acelerar o giro do estoque;

$\checkmark \quad$ Reduzir os índices de falta de produtos;

$\checkmark$ Melhorar a variedade e a satisfação do consumidor; $\checkmark \quad$ Aumentar as vendas por meio de melhor ajuste às necessidades dos consumidores;

$\checkmark \quad$ Diminuir a necessidade de "demarcações" pelo monitoramente contínuo do que está sendo vendido e do que está permanecendo nas prateleiras;

$\checkmark \quad$ Diminuir custos logísticos e administrativos devido ao processamento eletrônico de dados.

Além dos sistemas de reposição automática, a adoção de novas tecnologias no comércio entre empresas (código de barras, EDI, automação de pontos de vendas) estão gerando vários benefícios para a gestão de compras.

Através do EDI (Electronic Data Interchange), os componentes da cadeia de suprimentos (varejistas, distribuidores e fornecedores) podem trocar informações de: preços, produtos, pedidos de compras, níveis de estoques, avisos de recebimentos e notas fiscais, eliminando erros e agilizando o processo de abastecimento.

Em geral, as empresas que utilizam EDI precisam de serviços especializados em comunicação de dados, denominadas de VAN, ou seja, value added network, ou rede de valor adicionado.

Ao permitir o compartilhamento das séries de vendas entre fabricantes e varejistas, o sistema eletrônico reduz a incerteza em relação à demanda futura e permite um planejamento mais enxuto das operações, reduzindo os níveis de estoque ao longo de toda a cadeia de fornecimento.

\subsection{Modelos de evolução da área de Compras}

A mensuração do estágio de desenvolvimento da área de compras em uma organização indica se ela está preparada para as necessidades do mercado [8].

São propostas quatro fases de evolução, mostradas na figura 1 .

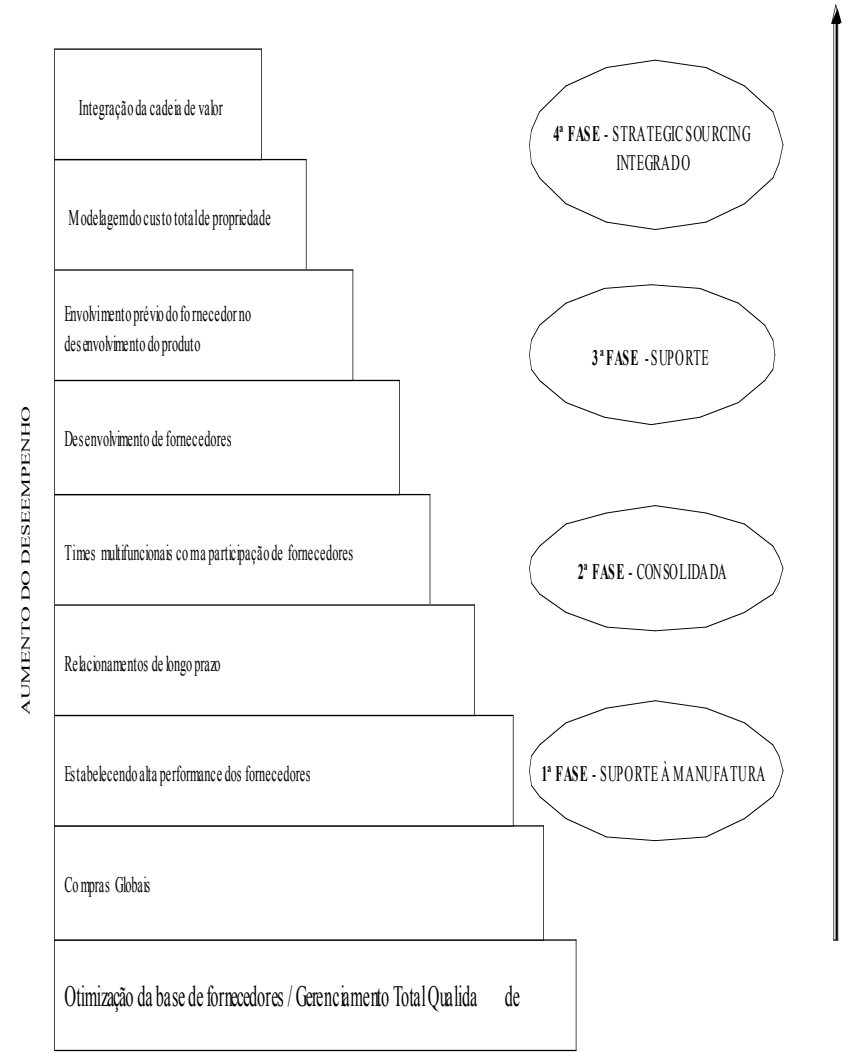


Figura 1: Evolução das Estratégias de Sourcing a partir de 1990

Fonte: Moncza et al. [8]

A primeira fase deste modelo refere-se à área de Compras como atividade de suporte. Neste estágio, existe uma abordagem passiva e a reação ocorre apenas quando existem reclamações quanto a não entrega de materiais no tempo correto, quanto à qualidade do produto ou quando os custos estão altos. As relações com os fornecedores são baseadas no modelo Darwiniano. As atividades realizadas são operacionais e os resultados mensurados a partir do número de ordens de compras emitidas, ou valores negociados por fornecedores.

A segunda fase inicia quando a área de compras torna-se uma função consolidada, ou seja, ocorre a centralização da área de compras com o objetivo de coordenar as compras regionais. Os compradores tornam-se responsáveis por classes de materiais e são estabelecidos acordos com fornecedores baseados na consolidação dos volumes, com o objetivo de redução de custos.

A terceira fase refere-se à evolução para a fase de suporte. Esta fase é a base para o estabelecimento de uma política estratégica de suprimentos. Neste momento, a área de Compras começa a estabelecer contratos de longo prazo com fornecedores críticos e inicia a racionalização da base de fornecedores. As relações com os fornecedores tornam-se mais amistosas e a relação de Balanced sourcing começa a ser empregada. Nesta fase, podem existir canais de informação informais entre atividades de engenharia, qualidade, compras, e finanças, embora ainda não sejam freqüentes as tomadas de decisões em conjunto.

O mais avançado estágio de Compras é o chamado Strategic Sourcing Integrado. Esta fase é caracterizada pela presença de várias iniciativas como, por exemplo: estudos de otimização de processos, engenharia, desenvolvimento de fornecedores, redução de tempo de entrega, envolvimento prévio dos fornecedores, e a realização de acordos de longo prazo. Nesta fase, ocorre alta integração entre as funções e a área de Compras passa a ser vista como parte chave da organização com foco no cliente. Os sistemas de informação incluem databases globais, evolução histórica de preços, informação de custos etc. A atividade de Compras passa a ter uma postura essencialmente pró-ativa que tem como objetivo a criação de valor.

Entre 1999 e 2004, o percentual de empresas brasileiras que possuem objetivos relacionados à criação de valor aumentou de $28 \%$ para $66 \%$ [11].

As prioridades dos presidentes das empresas, segundo estudo realizado pela AT. Kearney em 2004 passaram a ser: "Potencializar os talentos criativos dos fornecedores", "Integrar e fazer a cadeia de suprimentos mais eficiente" e "Criar valor através de efetiva inovação com nossos fornecedores chaves" [11].

A evolução de uma abordagem passiva para uma abordagem pró-ativa proporciona vários benefícios para a empresa. Redução de custos, aumento da qualidade dos produtos adquiridos e melhorias no desempenho de entregas são alguns dos resultados que podem ser quantificados. Além destes, Moncza et al. [8] acrescentam que podem ser obtidos valiosos insights através do entendimento total da cadeia de valor.

Como observado por Moncza [8], a otimização da base de fornecedores e o gerenciamento total da qualidade são algumas das técnicas empregadas em maior proporção pelas áreas de compras. Poucas empresas têm desenvolvido estratégias mais avançadas de Sourcing. A maioria das empresas ainda está na segunda e terceira fase de evolução (consolidação e suporte, respectivamente), em virtude do baixo nível de relacionamento com os fornecedores, falta de pessoal capacitado na área de compras e predomínio de atividades operacionais e táticas.

A evolução para a quarte fase (Strategic Sourcing Integrado) permitirá a obtenção de resultados mais consistentes no varejo e na indústria. Nesta fase, os executivos de compras tomam ações que afetam diretamente a melhoria da capacidade dos fornecedores, como por exemplo: desenvolvimento de fornecedores, envolvimento prévio, estabelecimento de altas performances, custo total de propriedade e integração da cadeia de valor.

Assim, para a análise da empresa objeto do presente estudo foi considerado o modelo de evolução da área de compras, descrito na figura 5. Em sua pesquisa, a autora buscou identificar as práticas de compras da empresa analisada, verificar as mudanças que ocorreram após a entrada dos concorrentes, diagnosticar o estágio atual de evolução e elaborar propostas para o aumento do desempenho da área de compras.

\section{Estudo de caso}

\subsection{A cadeia da construção Civil - 0 Construbusiness}

O setor de Construbusiness engloba além do segmento de material de construção, o segmento de edificações/construções pesadas, os serviços de imobiliária, os serviços técnicos de construção e por último, as atividades de manutenção de imóveis. A atividade definida dentro deste moderno conceito gera expressivo efeito multiplicador da economia.

Dentro do Construbusiness, o segmento de material de construção engloba as indústrias que produzem os materiais e as lojas de materiais de construção que farão a distribuição dos produtos ao consumidor final e que são objetos do presente estudo.

$\mathrm{O}$ setor de material de construção (indústria e lojas) no Brasil emprega 554.000 pessoas, fatura US\$ 
14,2 bilhões por ano e contribui com US\$ 3,5 bilhões em impostos. No tocante ao comércio varejista, as lojas de material de construção geram mais de 250.000 empregos, faturam mais de US\$ 5 bilhões e geram mais de US\$ 850 milhões em impostos.

No tocante ao comércio varejista de material de construção, atualmente existem mais de 100.000 lojas de material de construção no Brasil que garantem a entrega de produtos comercializados dentro deste segmento.

\subsection{Um Breve Histórico das lojas de material de construção no Brasil}

No Brasil, até o ano de 1990, predominavam os modelos de lojas de construção regionais, ou seja, lojas pequenas de até $1.000 \mathrm{~m}^{2}$ que comercializavam um número reduzido de materiais de construção (tijolos, cimentos, metais, cerâmica, tintas etc) cal. Em geral, o atendimento era feito no balcão, por vendedores especializados.

A partir de meados da década de 90, o varejo de material construção começou a modificar-se. Novos competidores chegaram ao Brasil e introduziram o modelo de loja, intitulado home center.

Enquanto em São Paulo, desde 1996, o mercado varejista de material de construção já sofria alterações, no Rio de Janeiro, o mercado de material de construção permanecia estável, uma vez que a concorrência ainda não havia chegado.

Nesta época, o grupo Casa Show (empresa tradicional de material de construção) era a principal rede de material de construção no Rio de Janeiro. Com mais de 20 anos de existência, dispondo de seis lojas espalhadas em pontos de boa localização, e com forte tradição no mercado carioca, o grupo Casa Show tinha o domínio do mercado local.

Porém, em 2001/02, os grupos Leroy Merlin e Casa e Construção (C\&C) visando a conquista de novos mercados resolveram investir no Rio de Janeiro, trazendo o modelo de loja home center, já existente em São Paulo.

A chegada da concorrência promoveu várias alterações no cenário carioca. Os concorrentes chegaram com uma política de preços agressiva, resultado do maior poder de barganha com os fornecedores e da necessidade de criar uma imagem de preços baixos a fim de fidelizar os consumidores.

As "guerras de preços" começaram a acontecer no Rio de Janeiro à semelhança do que ocorreu em São Paulo, reduzindo as margens de lucro deste segmento.

Neste novo cenário competitivo, as empresas regionais a fim de garantir a sua sobrevivência precisaram reformular-se e efetuar mudanças na área de compras, para permanecer competitivas.

Dentro deste contexto, foi realizado um Estudo de Caso na empresa Casa Show, líder carioca no segmento de material de construção, que mostrará as principais mudanças que foram feitas na gestão de compras após a entrada da concorrência.

\subsection{A Empresa Casa Show}

A empresa Casa Show, varejista de material de construção, é pertencente aos proprietários do grupo Sendas. O Supermercado Sendas foi criado pelo Sr. Manoel Sendas, em 1960. Com mais de 40 anos de existência tem grande tradição no mercado carioca. As lojas Sendas possuem mais de $4.000 \mathrm{~m}^{2}$ e 30 check outs e oferecem uma linha completa de

Atualmente, o grupo Casa Show dispõe de 8 lojas espalhadas pelo Rio de Janeiro (Bairro de Fátima, Barra da Tijuca, Tijuca, Ilha do Governador, Freguesia, Santa Cruz, Campo Grande além da tradicional loja de São João de Meriti). O grupo Casa Show tem mais de 600 funcionários e fatura mais de $\mathrm{R} \$ 150.000 .000,00$, anualmente.

Até o ano 2000, a Casa Show obteve altas margens de lucratividade. Neste período, a empresa tinha uma branda concorrência composta por lojas de bairro e por apenas, duas redes: a rede Crispum que atendia basicamente às construtoras e a rede Amoedo, que tinha como foco principal a venda de aquecedores e material elétrico. Porém, a partir de 2000, o mercado de material de construção do Rio de Janeiro sofreu alterações, devido à chegada de novos e fortes competidores.

Os grupos Leroy Merlin e Casa e Construção (C\&C), após o sucesso dos empreendimentos em São Paulo, resolveram investir no mercado carioca e inauguraram lojas de material de construção no modelo "home center", ou seja, lojas espaçosas com um amplo sortimento de itens para o lar, desde artigos pesados de materiais de construção (cerâmica, tintas, metais) até itens de decoração e jardinagem.

O grupo Casa Show precisou reestruturar-se a fim de enfrentar a nova concorrência. Em 2001, o Casa Show mudou a sua estrutura organizacional. A empresa contratou um novo executivo para assumir a direção geral da empresa e introduziu novos segmentos no mix (jardinagem, decoração e bazar). $\mathrm{O}$ modelo de loja de material de construção foi substituído pelo modelo home center.

\subsection{Principais Mudanças que ocorreram na gestão de compras, após concorrência.}

Nesta seção são apresentadas as principais mudanças que ocorreram na gestão de compras da Casa Show, após a entrada da concorrência e está estruturada nos itens Planejamento de Compras, Relacionamento com Fornecedores, Estrutura de Compras e Sistemas de Informação.

\subsubsection{Planejamento de Compras}

O planejamento de compras refere-se a como a empresa executa sua programação de compras. Abrange a elaboração do orçamento de compras, o estabelecimento das metas de compras e o gerenciamento dos níveis de estoque [10].

Até o ano 2000, o planejamento de compras não era executado. Com a diminuição das vendas ocasionada pela entrada dos novos concorrentes, a 
empresa precisou adaptar-se à nova condição e começou a dispor de uma programação anual de compras. Os objetivos da programação de compras foram: evitar excessos de estoque e melhorar o fluxo de caixa.

Atualmente, o orçamento da empresa é determinado pela área de planejamento financeiro. Com base na lucratividade desejada pela companhia, são estabelecidas as metas de vendas, despesas e margem. Após receber o orçamento feito pela área de planejamento financeiro, a área de compras divide este orçamento pelas categorias. $\mathrm{O}$ modelo de orçamento de compras utilizado é o sistema de cima para baixo, ou seja, a diretoria determina um valor monetário para as compras das empresas e com base nesta informação, a Gerência de Compras faz a distribuição do valor pelas diversas categorias de produtos. Para esta distribuição, são considerados os dados de participação de vendas e margem dos anos anteriores e a projeção de vendas de cada categoria para o ano seguinte.

Outra responsabilidade no planejamento de compras é a gestão de estoques. Com base no orçamento de vendas, cada categoria tem uma meta de estoque no final do mês. Com base nesta meta e na projeção de vendas, é estabelecida a meta de compras do mês.

Além de definir o mix a ser comprado, a área de compras também é responsável por definir as quantidades adquiridas para cada loja. Conforme as entrevistas realizadas, apesar do sistema de compras permitir o estabelecimento de parâmetros de estoque mínimo, máximo e ponto de reposição, estes não são utilizados. Como rotina diária, os compradores devem emitir um relatório que contém todos os produtos que estão com o estoque abaixo do mínimo definido pela empresa e definir a quantidade a ser comprada, de acordo com as seguintes variáveis:

$\checkmark \quad$ Localização do fornecedor - Se o fornecedor estiver no mesmo estado, compra-se uma quantidade menor, pois a entrega será efetuada em um prazo menor. Para fornecedores situados fora do estado e com prazo de entregas maiores, será efetuada um compra com maior quantidade.

$\checkmark \quad$ Sazonalidade do produto - Em função da sazonalidade do produto pode ser comprada uma quantidade maior do que a média dos últimos meses. Um exemplo é o caso de chuveiros e aquecedores. Em função da sazonalidade do produto, iniciada no inverno, a quantidade de produtos comprada será maior do que nos meses anteriores.

$\checkmark \quad$ Existência de promoção para o produto negociado - Alguns fornecedores oferecem descontos por quantidade. Estes descontos variam em função do volume do pedido ou, de forma cumulativa, de acordo com o volume comprado por um período de tempo (ex: no trimestre ou no ano). Através da concessão destes descontos, o fornecedor estimula o varejista a comprar quantidades maiores. Neste caso, o comprador deve avaliar o percentual de desconto concedido, o custo financeiro de estoque, a elasticidade do produto (aumento da demanda em função da redução de preço) e tomar a decisão de compra. O comprador deve avaliar com critério as propostas recebidas, pois muitos fornecedores com base na meta de venda que possuem fazem muitas ofertas para os compradores. O aceite das ofertas com quantidades acima do necessário, pode ocasionar um elevado valor de estoque e a falta de verba para compra de outros produtos.

Na empresa analisada, a não atualização dos parâmetros de estoque mínimo e máximo e o atraso de entrega de alguns fornecedores ocasionam, às vezes, a falta de determinados produtos no ponto de venda. Estes produtos são chamados pelos gerentes de lojas, de produtos "em ruptura". Esta situação é grave uma vez que o consumidor pode desistir de voltar à loja, por não encontrar o produto desejado.

\subsubsection{Relacionamento com Fornecedores}

Atualmente, a empresa Casa Show possui 45.000 itens em seu mix de produtos e mais de 550 fornecedores. Estes fornecedores são divididos de acordo com a participação nas vendas.

De acordo com esta classificação, o comprador faz a gestão de relacionamento com os fornecedores. No relacionamento com fornecedores A, por exemplo, são estabelecidas metas de desempenho. Estas metas são acompanhadas através de reuniões mensais entre o comprador e o fornecedor e reuniões trimestrais com a presença da Diretoria e Gerência de ambas as empresas. As principais metas são: vendas, margem e cobertura.

Antes da entrada da concorrência, o Casa Show exercia um grande poder de barganha sobre os fornecedores. Como principal varejista de grande porte no Rio de Janeiro, os compradores faziam pressões constantes nos fornecedores para concessão de bonificações e melhores condições de preços, diminuindo a lucratividade da indústria.

Com a entrada da concorrência, o panorama se inverteu. Os grupos Leroy Merlin e Casa e Construção $(\mathrm{C} \& \mathrm{C})$ por serem grupos nacionais e dispor de um maior número de lojas, passaram a dispor das melhores condições de negociação.

Para manter a competitividade e ter preços equivalentes a estas duas grandes redes, o Casa Show precisou se reaproximar dos fornecedores, mostrando as vantagens de se negociar com um grupo regional: maior autonomia, maior velocidade nas ações, conhecimento das exigências do consumidor local e equilíbrio do poder das grandes redes varejistas.

Outra mudança que está sendo implementada é a redução do número de fornecedores. A otimização da base de fornecimento tem os seguintes objetivos: aumentar o poder de barganha e melhorar o nível de relacionamento com os fornecedores selecionados.

A empresa analisada ainda não dispõe de contratos formais com os fornecedores. Todos os acordos são verbais.

Outros dois fatores que auxiliam no relacionamento com os fornecedores são: 
As áreas de compras dos maiores concorrentes (Leroy Merlin e C\&C) estão em São Paulo e por serem empresas de maior porte, a tomada de decisão é mais lenta.

Os grupos C\&C e Leroy Merlin são atendidos pelos vendedores de São Paulo. Logo, os vendedores / representantes que estão no Rio de Janeiro ainda vêem no Casa Show, como o maior grupo para negociação, uma vez que a empresa dispõe de 8 lojas e ainda detém a liderança no mercado do Rio de Janeiro, conforme ranking da Anamaco.

\subsubsection{Estrutura de Compras}

$\mathrm{Na}$ empresa analisada, todas as compras são feitas de forma centralizada, pela área de compras, que possui 5 compradores são responsáveis pela gestão das 7 categorias: Tintas e Chuveiros; Elétrica; Bazar; Decoração; Básico; Cerâmica e Acabamento. Cada comprador de categoria trabalha em conjunto com um assistente de compras.

Em função da falta de disponibilização de relatórios de gestão por parte do sistema de compras, o comprador e o assistente de compras gastam grande parte do seu tempo, com a elaboração de planilhas e a geração de informações, sobrando pouco tempo para realização de negociações e gerenciamento das relações com os fornecedores.

Todos os compradores têm nível superior e não existe rodízio de funções entre os compradores. Alguns assistentes de compras não têm nível superior. Todos os assistentes são oriundos da área de recebimento de mercadorias. A promoção de um assistente é rara, uma vez que a falta de nível superior e as atividades por ele executadas não o capacitam para uma promoção.

Quanto à freqüência de treinamentos, poucos cursos internos são promovidos, o que prejudica a atualização dos profissionais, em termos de tributos, gestão de categorias, finanças etc.

Quanto à forma como as compras são realizadas, estas são feitas exclusivamente pelos compradores, no escritório central da empresa. Nenhuma compra pode ser efetuada de forma descentralizada, pelo gerente da loja. As compras centralizadas têm o objetivo de aumentar o poder de barganha com os fornecedores em função do volume negociado e melhorar o nível de controle das mesmas.

Em cada loja, além dos gerentes, existem subgerentes que são responsáveis pela gestão de determinados segmentos e devem analisar de forma minuciosa: a exposição dos produtos, a precificação e a limpeza do setor. Semanalmente, o comprador faz uma visita à loja e juntamente com os gerentes e subgerentes elabora um plano de ação para melhoria do desempenho das vendas e lucratividade. Este plano de ação é acompanhado pela Gerência de compras e pela Gerência Regional.

\subsubsection{Sistemas de informação}

A empresa analisada dispõe de um sistema informatizado de Gestão de Compras que foi batizado de Material de Construção. Este sistema foi criado há 21 anos, pela equipe de informática da empresa.

No sistema utilizado pela área de compras, são analisadas as necessidades de reposição dos itens, digitados os pedidos de compras e realizados os cadastros de itens, fornecedores e preços.

Apesar de o sistema possuir parâmetros de estoques mínimos e máximos de cada item, estes não estão atualizados e a quantidade de compra é estipulada pelo comprador, com base nas vendas dos últimos seis meses e na sua experiência pessoal. Todos os pedidos de compras são enviados por e-mail para os fornecedores selecionados.

O sistema de compras, por ter sido desenvolvido há mais de 20 anos, foi feito em uma linguagem de programação que não é mais utilizada atualmente, o que cria dificuldades para atualizações ou modificações. Na equipe de informática, existe uma única pessoa que participou do seu desenvolvimento e é responsável por fazer todas as modificações necessárias.

No tocante à aquisição de um novo sistema de compras e a adoção de um programa de resposta rápida, a empresa ainda não tem nenhum projeto em andamento.

A troca eletrônica de dados entre fornecedores e varejista, também não é utilizada de forma abrangente. Apenas 20 fornecedores, ou seja, menos de $5 \%$ do total de fornecedores, trocam dados eletrônicos com o Casa Show através de uma empresa terceirizada, chamada Mercador. Os fornecedores participantes deste sistema recebem o pedido de compras automaticamente. Em contrapartida, o Casa Show recebe um "espelho" da nota fiscal, que é inserido automaticamente no sistema de recebimento Casa Show.

Os principais benefícios deste sistema são:

$\checkmark \quad$ O comprador não precisa enviar o pedido via e-mail. O pedido é enviado automaticamente.

$\checkmark$ O comprador recebe o "espelho da nota fiscal", facilitando a conferência das informações antes do recebimento.

$\checkmark \quad$ As informações da nota fiscal são colocadas no sistema do Casa Show, automaticamente, eliminando o trabalho manual da área de recebimento.

Quanto à entrega das mercadorias compradas pela empresa, esta pode ser feita diretamente nas lojas ou no centro de distribuição da empresa. Em geral, itens como tintas, louças, cerâmicas e móveis, que ocupam muito espaço nas lojas são comprados para entrega centralizada no centro de distribuição. Para estes itens existem parâmetros de estoque mínimo e máximo que garantem o ressuprimento automático destes produtos para as lojas.

Em relação às informações gerenciais que o sistema de compras oferece têm-se: vendas dos produtos nos últimos seis meses, curva $\mathrm{ABC}$ de itens, curva $\mathrm{ABC}$ de fornecedores, custo das últimas compras, saldo do estoque, margem objetivada, margem praticada, prazo de pagamento, histórico de 
recebimento dos produtos etc. Caso haja a necessidade de algum relatório que não está desenvolvido, esta demanda deverá ser submetida à área de informática que confeccionará o novo relatório.

A fim de auxiliar os compradores na tomada de decisão, existe apenas um módulo de decisão de compra, que calcula a margem bruta sobre a venda líquida do produto, com base nas informações de custo, impostos e frete, imputadas no sistema. Com a informação desta margem, o comprador negocia com o fornecedor, melhores condições de custo.

O sistema não dispõe de módulos onde são calculados (1) custo financeiro de estoque e (2) valor presente da aquisição, considerando os descontos de prazo de pagamento.

A empresa também não realiza a venda de produtos pela Internet.

\section{Propostas para aumento do desempenho da área de compras}

\subsection{Diagnóstico}

A presente pesquisa estudou as transformações que ocorreram na empresa Casa Show, após a entrada da concorrência, em relação aos quatro tópicos estratégicos: planejamento de compras, relacionamento com fornecedores, estrutura organizacional e sistemas de informação. A elaboração do diagnóstico destas transformações foi baseada nas entrevistas realizadas, na observação participante, levantamento de documentação e registros em arquivos. Abaixo, o resumo das principais modificações ocorridas:

No tocante ao planejamento de compras, a empresa passou a adotar uma programação que estipulava as metas mensais de compras de acordo com as metas de vendas.

A modalidade de orçamento que passou a ser adotada foi o modelo de cima para baixo, ou seja, a empresa determinava um valor para as compras em função da projeção de vendas e com base neste valor, a Gerência de Compras fazia a distribuição para os segmentos, de acordo com a participação de cada setor.

No tocante ao relacionamento com fornecedores, a empresa passou a ter um relacionamento mais amistoso com os seus parceiros comerciais, fazendo reuniões periódicas e traçando metas para aumento do desempenho. Além disto, reduziu a sua base de fornecimento, de 1000 fornecedores para apenas 550, com o objetivo de diminuir os custos de transação e aumentar o poder de barganha com os fornecedores selecionados, em função do maior volume de compras negociado.

A estrutura organizacional foi modificada com a revisão do organograma da área (contratação de um maior número de compradores, contratação de um Gerente de Compras e demissão dos funcionários não adequados ao novo perfil de compras). O modelo de gestão continuou a ser o modelo centralizado.

Não houve modificações nos sistemas de informação. A empresa não quis investir em um sistema integrado, o que dificulta a obtenção de relatórios de gestão e a otimização do trabalho do comprador e das outras áreas envolvidas. Pelo fato da empresa também não ter investido em um sistema de resposta rápida, os compradores continuam definindo a quantidade a ser comprada, acarretando dificuldades para que a empresa consiga obter maiores reduções dos níveis de estoque. A empresa também não acredita na venda de produtos pela Internet.

Abaixo, a tabela 2 mostra o diagnóstico da empresa em relação aos quatro tópicos estratégicos analisados.

\begin{tabular}{|c|l|}
\hline Tópicos Estratégicos & \multicolumn{1}{|c|}{ Diagnóstico } \\
\hline Planejamento de Compras & $\begin{array}{l}\text { Falta de planejamento estratégico. } \\
\text { Enfase no planejamento tático e } \\
\text { operacional. }\end{array}$ \\
\hline Relacionamento com fornecedores & $\begin{array}{l}\text { Evoluindo de relação darwiniana } \\
\text { para Balanced Sourcing }\end{array}$ \\
\hline Estrutura de compras & $\begin{array}{l}\text { Organização com especialização } \\
\text { funcional e centralizada }\end{array}$ \\
\hline Sistemas de informação & $\begin{array}{l}\text { Fase de reconhecimento - Estágio } \\
2 \text { - Sistema manual melhorado , } \\
\text { sistemas informatizados mas não } \\
\text { totalmente integrados aos outros } \\
\text { sistemas da empresa }\end{array}$ \\
\hline
\end{tabular}

Tabela 2: Diagnóstico da Empresa analisada em relação aos tópicos estratégicos

Com relação à classificação do estágio atual da área de compras proposto por Moncza et al. (1998) e descrito na seção 3.4 do trabalho, pelas características atuais da área de compras da empresa analisada, fica caracterizado que a mesma encontra-se na segunda fase de evolução, chamada de fase Consolidada.

\subsection{Propostas}

As propostas para aumento do desempenho da área de compras da empresa analisada estão descritas abaixo. Estas propostas são recomendadas pelos autores, com base na análise do estudo de caso e não permitirá generalizações para outras empresas. Cabe ressaltar, que no presente trabalho, não foi conduzido nenhum estudo de viabilidade que mensure os benefícios que poderão ser obtidos a partir desta evolução.

No tocante ao planejamento de Compras, após a concorrência, a empresa passou a dispor de uma programação, que auxiliou na redução de estoques e na melhoria do fluxo de caixa da empresa. Porém, o modelo utilizado de planejamento foi o de cima para baixo, ou seja, a Diretoria estipulava um valor para as compras e este valor era dividido pelas categorias. Para um planejamento mais eficaz, o modelo a ser utilizado deveria ser o planejamento interativo, ou seja, linhas gerais de orçamento seriam obedecidas pela Gerência de Compras e depois os compradores fariam uma estimativa em nível de produtos, depois pelas 
categorias, sendo finalmente, consolidado para a Empresa.

O planejamento interativo permitiria uma análise mais detalhada em nível de especificidades de cada produto (análise da média de consumo dos últimos meses, cobertura de estoque, nível médio de estoque) contribuindo para uma adequação correta dos valores de compras entre produtos e categorias.

Embora exista um planejamento operacional e tático da área de compras, este não está relacionado aos objetivos estratégicos da empresa. A visão predominante na empresa é funcional e não existe um planejamento estratégico geral que interligue os objetivos de todas as áreas da empresa. $\mathrm{Na}$ opinião dos autores do trabalho, deveriam ser criadas equipes multifuncionais, por exemplo, a área de compras deveria participar da definição do mix de produtos junto com a área de marketing e gerentes de lojas e atuar em conjunto com estas áreas na formulação de estratégias de vendas, encartes promocionais e ações no ponto de venda.

Adicionalmente, a empresa deveria dispor de um planejamento estratégico geral que fosse replicado para todas as áreas da empresa. Deveriam ser criadas metas de desempenho para cada área e instituído um programa de remuneração variável para os funcionários, de acordo com o atingimento das metas estabelecidas.

Em relação ao relacionamento com fornecedores, apesar desta relação ter evoluído após a entrada da concorrência, ainda falta a adoção de políticas mais consistentes. A assinatura de contratos de longo prazo com os fornecedores poderia incentivar melhorias na cadeia de suprimentos (reduções de estoque na cadeia de suprimentos, melhorias do prazo de entrega dos fornecedores e lançamentos de produtos com exclusividade). Deveria ser instituída uma premiação que estimulasse o compartilhamento de ganhos com os fornecedores que atingissem ou superassem as metas estabelecidas.

Quanto ao modelo da estrutura de compras, esta deveria ser mista, ou seja, a centralização de compras devia ocorrer para os itens que concentram os maiores volumes financeiros, e para alguns segmentos (exemplo: itens de decoração e iluminação) a compra deveria ser descentralizada, feita pelo gerente da loja. A adoção desta estrutura diminuiria o número de itens gerenciados pelo comprador e favoreceria a compra de um mix mais adequado ao consumidor de cada loja. Deveria haver mais investimentos para o treinamento dos compradores, principalmente no tocante à gestão de categorias.

Em relação ao sistema de informações, a empresa deveria investir na aquisição de um ERP, que facilitaria o manuseio das informações de todas as áreas em uma única base de dados. Adicionalmente, a empresa deveria investir em um programa de resposta rápida e na troca eletrônica de dados entre fornecedor e o Casa Show. A adoção destes sistemas traria os seguintes benefícios:
Gestão de estoques - A adoção de um sistema de resposta rápida permitiria que a empresa trabalhasse com estoques mais reduzidos, diminuindo $o$ investimento ao longo de toda a cadeia produtiva.

Racionalização do processo de compras - A troca de informações eletrônica (pedidos de compras, espelhos de notas fiscais, tabela de produtos) diminuiria o trabalho operacional dos compradores e assistentes, gerando maior tempo livre para a realização de negociações.

Gestão de informações - A existência de relatórios gerenciais permitiria que o comprador gastasse menos tempo na elaboração de planilhas e facilitaria o processo de negociação com os fornecedores, analisando todas as variáveis importantes para a tomada de decisão da compra, como por exemplo, prazo de pagamento, quantidade comprada, freqüência de compras, de modo que o comprador escolhesse a alternativa que trouxesse melhores resultados para a empresa.

\section{Considerações finais}

O objetivo final deste trabalho é a elaboração de propostas para aumento de desempenho da área de compras de uma empresa de capital nacional, de estrutura familiar, líder no segmento de material de construção no Rio de Janeiro.

Para a realização deste objetivo, foi conduzido um estudo de caso na referida empresa com as seguintes finalidades:

1) Identificar as transformações que ocorreram na área de compras desta empresa após a entrada da concorrência. Para a elaboração deste diagnóstico, esta pesquisa baseou-se na análise de quatro tópicos estratégicos: planejamento de compras, estrutura organizacional, relacionamento com fornecedores e sistemas de informação, que segundo a CAPS (Center for Advanced Purchasing Studies) estão entre os mais adequados para a identificação das melhores práticas em Compras.

2) Diagnosticar o estágio atual de desenvolvimento da área de compras, conforme modelo proposto por Moncza et al. [8].

O Estudo de Caso na empresa analisada trouxe as seguintes conclusões:

$\checkmark$ A área de compras ainda exerce um papel operacional na empresa analisada. Pelas características encontradas na área de compras da empresa analisada, a empresa classifica-se no estágio 2 de desenvolvimento, conforme modelo de evolução proposto por Moncza \& Trent [8].

$\checkmark \quad$ Para a evolução para um patamar mais estratégico dentro da organização, seria necessária a adoção de mudanças mais consistentes em relação aos quatro tópicos estratégicos analisados (planejamento de compras, relacionamento com fornecedores, estrutura organizacional e sistemas de informação). 
$\mathrm{Na}$ parte final do presente trabalho, foram feitas recomendações para o aumento do desempenho da empresa analisada, conforme abaixo:

(1) Melhorias no relacionamento com fornecedores: $O$ nível de relacionamento com os fornecedores poderia ser melhorado, a partir da assinatura de contratos de longo prazo com compartilhamento de resultados. Além disto, a empresa analisada deveria criar um relacionamento harmonioso com os fornecedores, de modo que eles fossem estimulados a criar produtos exclusivos para a empresa, fazer promoções conjuntas no ponto de venda, e identificar oportunidades de melhorias de vendas.

(2) Otimização dos processos de compras através da utilização de sistemas de informação: A empresa deveria analisar a aquisição de um ERP, a fim de facilitar a integração das informações entre as áreas, investir em um programa de resposta rápida e na troca eletrônica de dados com os fornecedores. Estes investimentos ocasionariam redução dos níveis de estoques, diminuição da falta de produtos no ponto de venda e otimização do trabalho do comprador.

(3) Realização de um planejamento estratégico que interligasse os objetivos de todas as áreas: A empresa deveria dispor de um planejamento estratégico geral que fosse replicado para todas as áreas da empresa. Deveriam ser criadas metas de desempenho para cada área e instituído, um programa de remuneração variável para os funcionários, de acordo com o atingimento das metas estabelecidas.

Em relação ao planejamento de compras, as estratégias deveriam estar integradas aos objetivos da organização e ajustada às outras áreas da empresa. Adicionalmente, deveriam ser estudadas as estratégias adotadas pelos concorrentes, identificadas as ameaças e oportunidades nos mercados de suprimentos e finalmente, elaborado um plano estratégico de suprimentos que tivesse foco nas áreas de maior potencial em termos de contribuição e fornecesse vantagens competitivas para a organização.

Deveria haver uma maior integração entre as áreas (marketing, compras, administrativa, logística). A empresa deveria criar equipes multifuncionais para executar projetos de melhoria. Atualmente, a visão funcional predomina na empresa, fazendo com que os benefícios não sejam capturados ao longo de toda a cadeia.

(4) adoção de uma estrutura organizacional eficaz: Deveria ser adotado um modelo misto de compras, combinando a adoção de compras centralizadas para os segmentos com maior participação no negócio e a adoção de compras descentralizadas para itens de decoração e elétrica, que exigem a percepção do consumidor local.

Deveria ser feito um maior investimento em treinamento da equipe de compras. Os compradores precisariam ser bem capacitados para tomar melhores decisões, analisando aspectos financeiros e tributários. Para isto, deveriam ser promovidos cursos constantes de aperfeiçoamento profissional.
Desta maneira, conclui-se que o presente artigo apresentou um modelo de diagnóstico da área de compras a partir da abordagem de quatro tópicos estratégicos e fez propostas para o aumento do desempenho e para a evolução da área de compras para um patamar mais estratégico. Cabe ressaltar que, por tratar-se de um estudo de caso realizado em uma empresa específica, estas propostas devem ser visualizadas na perspectiva de sugestões, a partir das quais as empresas varejistas poderão adaptar as propostas de melhorias de acordo com a necessidade e particularidades do campo em que atuam.

Como sugestões de trabalhos futuros relacionados ao tema compras, pode-se destacar: (1) aplicação de novas tecnologias de informação no relacionamento entre varejistas e fabricantes, (2) o início de uma série de pesquisas dentro da área de comércio varejista de material de construção e (3) estudo sobre as tendências da área de compras no varejo.

\section{REFERÊNCIAS BIBLIOGRÁFICAS}

[1]. BAILY, P. et al. Compras: princípios e administração. Tradução de Ailton Bomfim Brandão. São Paulo: Editora Atlas, 2000.

[2]. CHAVES, A. F. A. R. Estudo das variáveis utilizadas na decisão de compras no comércio varejista de alimentos de auto-serviço supermercados. Dissertação (Mestrado). USP, São Paulo, 2002.

[3]. CONZ, C. Os 50 maiores varejistas e os 50 maiores atacadistas do setor de material de construção. Revista Anamaco. N.160, p.24-118, 2006.

[4]. HENDRICK, T. E. A Multi-Country Study of Strategic Topics in Purchasing and Supply Management. Disponível em: $<\underline{\text { http://capsresearch.org }>\text {. Acesso em: 02/06/2006 }}$

[5]. HUGHES, T. Shareholder and stakeholder expectations - embracing the next wave of change. Disponível em: http://www.futurepurchasing.com. Acesso em : 02/02/2006

[6]. LASERTE, T. M. Balanced Sourcing Cooperation and Competition in Supplier Relationships. California: Booz-Allen \& Hamilton, 1998.

[7]. LIMA, J. C. Um estudo sobre a reconfiguração da função compras em empresas do setor automotivo. Tese (Doutorado em Engenharia).USP, São Paulo, 2004.

[8]. MONCZA, R., TRENT, R., HANDFIELD, R. Purchasing and Supply Chain Management. Ohio: Thomson Publishing, 1998. 
[9]. NEVES, J. L. Adaptação às condições do varejo brasileiro: Lições do caso Wal Mart. Varejo competitivo. Coordenação: Cláudio Felisoni Ângelo e José Augusto Giesbrecht da Silveira. São Paulo: Editora Atlas, 1997.

[10]. PARENTE, J. Varejo no Brasil. São Paulo: Atlas, 2000.

[11]. RASCKE, B. Strategic Challenges for Leading Edge Purchasing Executives. Disponível em: $\leq \mathrm{http}: / /$ www.atkearneyprocurementsolutions.com $>$. Acesso em: 01/05/2006.

[12]. RIGGS, D., ROBBINS, S. Supply Management Strategies. HSM Management-Book Summary 2. São Paulo. Out-Dez, p.61-83, 2001.

[13]. WANKE, P. O paradigma do ressuprimento enxuto: armadilha na gestão do fluxo de materiais entre elos da cadeia de suprimentos. Disponível em: $\quad<$ http:// www.cel.coppead.ufrj.br/frimplement.htm $>$. Acesso em: 21/03/2006.

[14]. WANKE, P. Aspectos fundamentais da gestão de estoques na cadeia de suprimentos. Disponível em: $\leq \mathrm{http}$ ://www.cel.coppead.ufrj.br/frimplement.htm> . Acesso em: 20/04/2006.

[15]. YIN, R. Estudo de caso - planejamento $e$ métodos. São Paulo: Bookman, 2005.

\section{Os Autores:}

ROSANGELA VILELA DOS SANTOS, Mestre em Administração (Ibmec/RJ), Gerente de Compras do CasaShow, interessada em pesquisas sobre Estratégia e Operações.

LUIZ ALBERTO NASCIMENTO CAMPOS

FILHO, Engenheiro Mecânico (UFF/RJ), Mestre em Ciências (ITA/SP), Doutor em Engenharia de Produção (USP/SP), Professor das Faculdades Ibmec RJ, interessado em pesquisas sobre Gestão Internacional e Estratégia. 